Article

\title{
Impact of Pretreatment of Metal Glass Fe70Cr15B15 on Anodization in 1-butyl-3-methylimidazolium Tetrafluoroborate Ionic Liquid
}

\author{
Olga Lebedeva ${ }^{1}$, Victoria Snytko ${ }^{1}$, Irina Kuznetsova ${ }^{1}$, Konstantin Kalmykov ${ }^{1}$, \\ Dmitry Kultin ${ }^{1}$, Natalia Root ${ }^{1}$, Svetlana Philippova ${ }^{1}$, Sergei Dunaev ${ }^{1}$, Alexandre Zakharov ${ }^{1,2}$ \\ and Leonid Kustov 1,3,4,* \\ 1 Department of Chemistry, Lomonosov Moscow State University, 119991 Moscow, Russia; \\ lebedeva@general.chem.msu.ru (O.L.); less_98@mail.ru (V.S.); kuznetsowair@yandex.ru (I.K.); \\ kbkalmykov@mail.ru (K.K.); dkultin@general.chem.msu.ru (D.K.); natalia_root@mail.ru (N.R.); \\ s_philippova@mail.ru (S.P.); dunaev@general.chem.msu.ru (S.D.); zakh-alex@yandex.ru (A.Z.) \\ 2 Moscow N.E. Bauman State Technical University, Department of Fundamental Sciences, \\ 2-ya Baumanskaya 5, 105005 Moscow, Russia \\ 3 N.D. Zelinsky Institute of Organic Chemistry, Russian Academy of Sciences, Leninsky Prospect 47, \\ 119991 Moscow, Russia \\ 4 National Science and Technology University “MISiS", Leninsky prosp. 4, 119991 Moscow, Russia \\ * Correspondence: lmk@ioc.ac.ru; Tel.: +7-495-939-5261
}

Received: 19 March 2020; Accepted: 28 April 2020; Published: 29 April 2020

\begin{abstract}
The impact of preliminary treatment (mechanical abrasion; chemical etching and anodization in ionic liquid) on the surface structure and corrosion behavior of Fe70Cr15B15 metal glass was studied. The detachment of the anodic oxide film from untreated Fe-amorphous alloy under anodization in ionic liquid was observed for the first time. The formation of hexagonal nanostructures (cells) on the surface of the Fe70Cr15B15 alloy after mechanical abrasion and following anodization in 1-butyl-3-methylimidazolium tetrafluoroborate $\left([\mathrm{Bmim}]\left[\mathrm{BF}_{4}\right]\right)$ ionic liquid was also detected for the first time. Electrochemical corrosion of the initial and pretreated amorphous alloy was tested in a $\mathrm{Na}_{2} \mathrm{SO}_{4}$ aqueous solution. The resistance to corrosion was found to be enhanced slightly after mechanical abrasion. The sample with hexagonal nanostructures obtained after anodization of the mechanically abraded sample demonstrated a more significant anodic shift in the corrosion potential $\left(E_{\text {corr }}=+379 \mathrm{mV}\right)$ compared with that for the initial alloy $\left(E_{\text {corr }}=-125 \mathrm{mV}\right)$.
\end{abstract}

Keywords: metallic glasses (or amorphous metals); electrochemical oxidation; ionic liquid; corrosion; self-assembly

\section{Introduction}

In recent years, the chemistry of metal glasses (amorphous alloys) has been intensively developed owing to the discovery of new properties and applications of these materials. Compared with crystalline materials, the liquid-like atomic structure, with no grain boundaries, dislocations, and phase segregation confers bulk metallic glasses superior mechanical properties involving high fracture strength and large elastic deformation [1]. Fe-based metal glasses were found to exhibit a higher strength, hardness, and corrosion resistance than other amorphous and crystalline alloy materials [2]. Amorphous alloys are widely applied in micro- and nano-electromechanical devices due to their outstanding physical and electrochemical properties [3]. Amorphous alloys are of particular interest as medical materials, for which one of the requirements is resistance to various types of corrosion $[4,5]$. 
The corrosion resistance of steels doped with various non-metallic elements is of permanent interest. Chromium is known to be one of the most important alloying additives to iron in manufacturing stainless steel to bring the improved anticorrosive features against aggressive aqueous solutions [6]. Chromium is known as a passive promoter due to the combination of strong chromium-oxygen bonding as opposed to the weak metal-metal bond strength, which is favorable for the stability of the passive film and the rapid nucleation and growth of the oxide. The higher the chromium content, the lower the corrosion rate of steel [7].

Stainless steels alloyed with nonmetal elements are also of growing interest due to the formation of amorphous materials providing new physical and electrochemical features. One of the most attractive properties of these materials is their corrosive resistance in aqueous solutions. Therefore, the alloy corrosion resistance was improved by the increase in the boron content [8].

Preliminary treatment of the materials in question also affects their corrosive resistance and the surface structure. Nitric, phosphoric, sulfuric acid pretreatments resulted in a strong beneficial influence on the pitting resistance and wear rate of stainless steel [7]. Electrochemical oxidation in aqueous solutions does not always lead to protective oxide film formation and a decrease in the corrosion rate. The best corrosion behavior and long-term stability were obtained after immersing the $\mathrm{FeNiCr}$ alloy in a mixed acid solution as opposed to using the electrochemical method to treat $\mathrm{FeNiCr}$ alloy [9]. The anodic oxidation of alloys in non-aqueous media provides a real opportunity to change the surface chemistry of metal or alloy in a benign manner and to improve anticorrosive properties. The chemical etching of Fe-alloys in an acetone solution of citric acid, benzoic buffer, sodium hydroxide has been poorly studied to date. There are relatively few detailed quantitative studies of the changes in the surface structure as a function of treatment [10].

Ionic liquids (ILs) demonstrate the Green Chemistry principles via numerous examples and exhibit a wide window of electrochemical stability, which makes them benign electrolytes for the processes that cannot be performed in other electrolytes. ILs based on the tetrafluoroborate anion are hydrophobic and rather stable; they are also not subject to hydrolysis with the formation of $\mathrm{HPO}_{2} \mathrm{~F}_{2}$, $\mathrm{H}_{2} \mathrm{PO}_{3} \mathrm{~F}, \mathrm{H}_{3} \mathrm{PO}_{4}$, and $\mathrm{HF}$, unlike hexafluorophosphate ionic liquids [11].

Anodic oxidation of some metals in ionic liquids leads often to polishing of the surface of the electrode [12-16]. In some cases, the etching (pitting) of the electrode surface is also observed. In general, the result of anodization depends on the nature of the metal, alloying additives, surface morphology, properties of surface oxide films, type of ionic liquid (hydrophobic/hydrophilic), presence/absence of water, temperature and other factors [17-19]. The influence of the nature of the ionic liquid (hydrophilic/hydrophobic) was studied during the anodization of $\mathrm{Ti}$, $\mathrm{Ni}$, crystalline steel. It was found that cellular nanostructures are obtained in hydrophobic ionic liquids (BMIMNTf $\mathrm{BMIMBF}_{4}$ ) [19]. Nanotubes, nanorods of corresponding oxides are formed in hydrophilic IL (BMIMCl). Previously, the authors found that metallic glasses are the most favorable materials to produce surface nanostructures by anodic oxidation in ionic liquids [17].

Along with the composition of an amorphous alloy, the preliminary treatment of the sample before anodization is also an important factor that governs the formation of surface nanostructures and affects the anticorrosive properties and the mechanical response. A change in the film composition at the fixed thickness $(800 \mathrm{~nm})$ involves a change of the fracture morphology and of nanoindentation hardness, but also a change in the local atomic environment in terms of elastic properties, mass density, activation volume, and the position and amplitude of diffracted halos [1]. The authors [20] reported the successful fabrication of freestanding fully amorphous $\mathrm{Zr} 65 \mathrm{Ni} 35$ metallic glass tensile test specimens avoiding Focus Ion Beam milling, while studying a broad range of geometries to investigate how the size affects the strength and ductility. Here, mechanical (abrasion) and chemical (etching) preliminary treatments have been chosen. The chemical etching in an acetone solution of citric acid, benzoic buffer, sodium hydroxide makes it possible to dissolve only the surface oxide without affecting the metal itself.

The corrosion behavior was investigated for Fe-based metallic glasses in $9.7 \mathrm{M}$ and $0.1 \mathrm{M}$ $\mathrm{H}_{2} \mathrm{SO}_{4}[6,21]$. The electrochemical behavior of amorphous Fe-Cr-B alloy in neutral aqueous $(\mathrm{pH}=7)$ 
and non-aqueous media has been poorly studied to date and the formation of nanostructures on this solid has not been considered.

The aim of this work was to elucidate the effect of preliminary treatment (mechanical abrasion; chemical etching in an acetone solution of citric acid, benzoic buffer, sodium hydroxide) on the corrosive properties of amorphous alloy Fe70Cr15B15 in an aqueous $0.1 \mathrm{M} \mathrm{Na}_{2} \mathrm{SO}_{4}$ solution $(\mathrm{pH}=7)$ and the surface topographical texture of the pretreated samples after anodic oxidation in 1-butyl-3-methylimidazolium tetrafluoroborate ([Bmim] $\left.\left[\mathrm{BF}_{4}\right]\right)$ ionic liquid (IL).

\section{Materials and Methods}

[Bmim] $\left[\mathrm{BF}_{4}\right]$ ionic liquid (purity 99.5\%) (ABCR GmbH, Karlsruhe, Germany) was used as purchased. The content of water in IL was $5000 \mathrm{ppm}$ (determined by titration according to Fischer by the 899 Coulometer (Metrohm)). Acetone, benzoic and citric acids, sodium hydroxide, sodium sulfate, and sodium benzoate (all with a purity of $99.9+\%$ ) were used as received.

The rotating-cylinder method has been applied for the preparation of the amorphous iron-chromium-boron alloy. The starting materials were B (purity 99.99\%), Fe (purity 99.95\%), and electrolytic $\mathrm{Cr}$ (purity 99.95\%). The amorphous Fe70Cr15B15 alloy (AA) was prepared in an electric arc furnace in an argon atmosphere with the triple remelting procedure. Impinging a stream of molten alloy on the outer surface of a rotating cylinder in an argon atmosphere was used to convert the obtained crystalline sample to the amorphous state [22]. The ribbon parameters were: width 7-10 mm, thickness $10 \mu \mathrm{m}$. The preparation conditions were determined by the necessity to obtain the material in the amorphous state.

The surface morphology and composition of the samples were studied using a scanning electron microscope EVO-50 Zeiss with an EDX (Energy-dispersive X-ray spectroscopy) analyzer (Zeiss AG, Jena, Germany) and an inverted routine microscope for materials ZEISS Axio Vert.A1 (Zeiss AG, Jena, Germany).

The X-ray phase analysis was carried out by means of a DRON-3 diffractometer $\left(\mathrm{Cu}-\mathrm{K}_{\alpha}\right)$ (Bourevestnik, JSC, St. Petersburg, Russia). According to X-ray phase analysis, a blurred halo is observed. The blurred halo indicates the amorphous state of this alloy. The amorphous state of the alloy was confirmed by differential scanning calorimetry. DSC (Differential scanning calorimetry) measurements were carried out with a Jupiter STA 449 F1 apparatus (NETZSCH GmbH, Selb, Germany) in He. The temperature scanning rate was $20 \mathrm{~K} \mathrm{~min}^{-1}$. The apparatus was calibrated by the melting temperatures of standard samples of metals ( $\mathrm{In}, \mathrm{Sn}, \mathrm{Bi}, \mathrm{Zn}, \mathrm{Al}, \mathrm{Au}$ ) provided by the NETZSCH company. Calibration and experiment were performed under the same conditions.

The electrochemical experiments were carried out in three-electrode cells (the volume of the ionic liquid was $2 \mathrm{~mL}$ ) with non-separated compartments under galvanostatic conditions (the current density $i=12.5 \mathrm{~mA} \mathrm{~cm}^{-2}$ ) using an AUTOLAB PGSTAT 302N potentiostat (Metrohm AG, Herisau, Switzerland). Electrochemical anodizing was carried out at room temperature in air for $100 \mathrm{~s}$ in $[\mathrm{Bmim}]\left[\mathrm{BF}_{4}\right]$.

The areas of the working and auxiliary AA electrodes were 0.4 and $0.6 \mathrm{~cm}^{2}$, respectively. The distances between the working and auxiliary electrodes, auxiliary and reference electrodes, and working and reference electrodes were $0.3-0.4,0.5-0.6$, and $0.3-0.4 \mathrm{~cm}$, respectively. The electrodes were rinsed with acetone in an Elmasonic $\mathrm{P} 30 \mathrm{H}$ ultrasonic cleaning unit (Elma) at $37 \mathrm{kHz}$ and dried in Ar until they reached constant weight. A silver wire was used as a quasi-reversible reference electrode. The potential of the silver wire was constantly calibrated vs. the standard $\mathrm{fc} / \mathrm{fc}^{+}$electrode.

Corrosion tests were carried out under natural aeration in $0.1 \mathrm{M} \mathrm{Na}_{2} \mathrm{SO}_{4}$ prepared by using reagent-grade chemicals and deionized water. The volume of the solution was $100 \mathrm{~mL}$. The area of the working AA electrode was $0.4 \mathrm{~cm}^{2}$. The linear polarization curves were measured at room temperature with a potential sweep rate of $1 \cdot 10^{-3} \mathrm{~V} \mathrm{~s}^{-1}$, starting from the cathodic region. $\mathrm{An} \mathrm{Ag} / \mathrm{AgCl}$ electrode was used as a reference electrode. The corrosion potential $\left(E_{c o r r}\right)$ and polarization resistance $(P R)$ were calculated using the standard procedure (Nova 2.1.3, Linear polarization, Corrosion rate analysis) 
for the AUTOLAB PGSTAT 302N potentiostat. Corrosion measurements were performed at least in duplicate to ensure the repeatability of the results.

Before anodizing, the samples were sonicated in acetone for $1 \mathrm{~h}$ at room temperature. Pretreatment of AA included mechanical abrasion, chemical etching with solutions of citric acid $(0.013$ and $1.6 \mathrm{M})$ and a benzoic acid buffer solution (BB) [benzoic acid $(0.013 \mathrm{M})$ and sodium benzoate $(0.013 \mathrm{M})$ ] in acetone; sodium hydroxide in water $(7.75 \mathrm{M})$ and in acetone $(0.013 \mathrm{M})$. The samples being exposed to etching solutions for $1 \mathrm{~h}$ were rinsed with acetone and dried in air.

The working electrode was abraded with emery paper for $5 \mathrm{~min}$, as in, e.g., [13]. The sample without preliminary treatment was anodized just after the treatment with acetone.

\section{Results and Discussion}

\subsection{Anodic Oxidation of Fe70Cr15B15 in Ionic Liquid (IL)}

Particularly interesting data were observed for electrochemical oxidation of AA in IL. The results of anodizing of the Fe70Cr15B15 amorphous alloy in IL were found to depend on the state of the electrode surface. Figure 1a demonstrates galvanostatic transients obtained for the untreated, mechanically abraded, and chemically pretreated samples, with the latter alloy being treated with citric acid, benzoic buffer, and $\mathrm{NaOH}$ acetone solutions. The samples were exposed to reagents in acetone for $1 \mathrm{~h}$ at room temperature to react with surface oxide films.

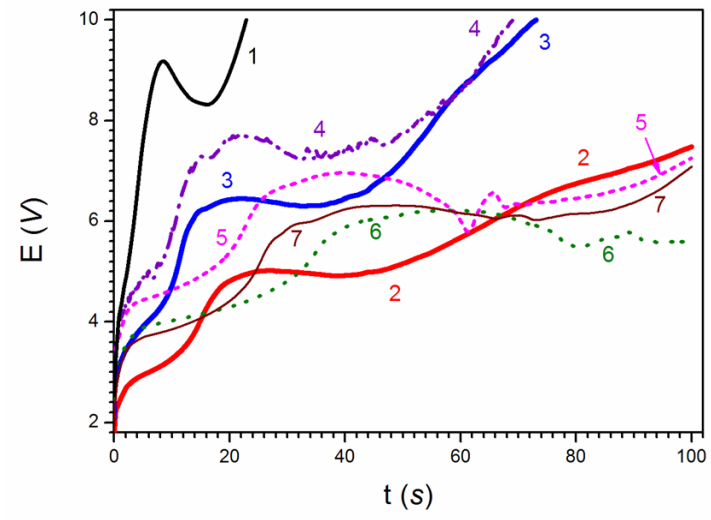

(a)

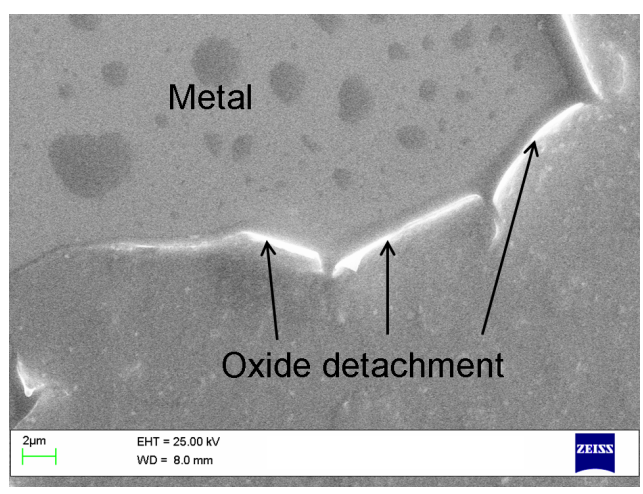

(b)

Figure 1. Galvanostatic anodic oxidation of the Fe70Cr15B15 amorphous alloy in 1-butyl-3-methy limidazolium tetrafluoroborate: (a) Potential $(E)$ as a function of time $(t)$ for: 1-untreated sample, 2-mechanically abraded, 3 and 4-preliminarily etched with 1.6 and $0.013 \mathrm{M}$ acetone solutions of citric acid, respectively, 5-preliminarily treated with an acetone benzoic buffer solution ( $0.013 \mathrm{M}$ benzoic acid $+0.013 \mathrm{M}$ sodium benzoate), 6-preliminarily treated with a $\mathrm{NaOH}$ acetone solution, 7-preliminarily treated with an $\mathrm{NaOH}$ aqueous solution; (b) SEM images of the Fe70Cr15B15 amorphous alloy surface of the abraded sample illustrating the detachment of the anodic oxide film after anodic oxidation in IL and oxide-free metal surface (the loose piece of oxide).

The pretreatment of AA with citric acid and sodium hydroxide solutions in acetone results in the total or partial removal of the surface oxide films, inasmuch as the oxides and hydroxides of $\mathrm{Fe}$ and $\mathrm{Cr}$ are known to be amphoteric. The reagents presumably act as a mild acid and base in a nonaqueous solvent.

It is seen from the potential-time transients that there are nonmonotonic upward slopes in the potential $(E)$ with time for the unpretreated AA electrode (see 1, Figure 1a). This feature may be accounted for by the occurrence of two processes: 
- The increase in the oxide film thickness on the surface of the electrode as a result of the electrochemical galvanostatic oxidation;

- The discontinuity of the oxide film due to a loss of the adhesion with the metal surface (detachment) [23].

The increase in the oxide film thickness brings about an electrode potential growth. The following detachment of the anodic oxide film from the alloy results in the electrode potential drop due to the development of the oxide-free metal surface. Detachment of the anodic oxide films from the metal surface was observed for aluminum and its alloys, e.g. [24-26]. Detachment of the anodic oxide film from the amorphous Fe-alloy was detected for the first time. The surface state of the sample under consideration at this moment is shown in Figure $1 b$.

At the same time, no distinct transient drops in the potential for the samples pretreated with citric acid, a $\mathrm{BB}$ acetone solution, and $\mathrm{NaOH}$ solutions in acetone and water were detected (Figure 1a curves 3-7). The pretreatment of AA samples leads to the total or partial removal of the native oxide film. Therefore, the following anodization of the etched AA samples gives rise to the electrochemical oxide film and results in a monotonic potential increase.

It should be noted that anodization in IL influences the surface state differently depending on the pretreatment procedure. Only for the mechanically abraded sample, a peculiar pattern was found on the metal glass surface. Anodization of this sample in IL led to the generation of hexagonal nanostructures (cells) (Figure 2a).

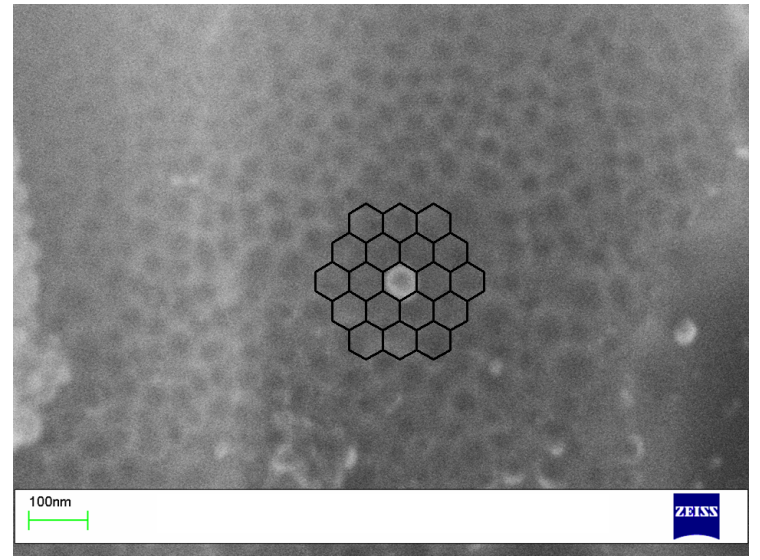

(a)

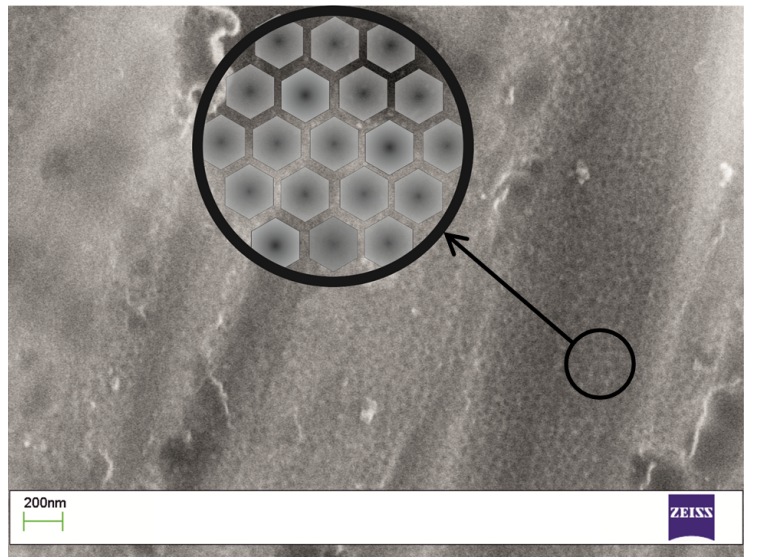

(b)

Figure 2. (a) SEM image of the Fe70Cr15B15 alloy after abrasion and anodization in IL for $100 \mathrm{~s}$ $\left(i=12.5 \mathrm{~mA} \mathrm{~cm}^{-2}\right.$ ) before electrochemical anodic oxidation in an $0.1 \mathrm{M} \mathrm{Na}_{2} \mathrm{SO}_{4}$ aqueous solution; (b) SEM image of the Fe70Cr15B15 alloy after abrasion, anodization in IL for $100 \mathrm{~s}\left(i=12.5 \mathrm{~mA} \mathrm{~cm}^{-2}\right)$, and electrochemical anodic oxidation in the $0.1 \mathrm{M} \mathrm{Na}_{2} \mathrm{SO}_{4}$ aqueous solution.

The variations in the potential during anodization of the AA sample preliminarily etched with a solution of sodium hydroxide in water and acetone are in accordance with the results obtained for the samples preliminarily treated with citric acid. The preliminary treatment of AA with alkaline solutions leads to the pitting of the electrode surface in both cases. The solvent nature (acetone/water) does not influence the results of anodization in IL. The surface of AA also undergoes effective etching.

It is reasonable to connect the deterioration of the anticorrosive properties of AA after pretreatment with a change in the surface composition of the electrode due to its enrichment in $\mathrm{Cr}$, as has been found for austenitic stainless steel $[27,28]$. The bulk Cr:Fe ratio for the initial alloy is $1: 4.67$. The surface Cr:Fe ratio for the initial alloy according to EDX analysis is 1: 4.32 (Table 1). The change in the surface composition in comparison with the bulk composition of the electrode probably occurs due to some surface enrichment in $\mathrm{Cr}$. According to the EDX data, there was no considerable enrichment on 
the surface of AA during anodizing in IL. This fact allowed us to exclude the contribution of this mechanism (Table 1).

Table 1. EDX data for the surface composition of the initial sample and those obtained after anodizing of amorphous Fe70Cr15B15 alloy (AA) in ionic liquid (IL) used without pretreatment (untreated) and after pretreatment with benzoic acid buffer solution (BB) (etched), etched and anodized in IL.

\begin{tabular}{ccccc}
\hline \multirow{2}{*}{ Sample } & \multicolumn{3}{c}{ Mean Value (at. \%) } & \multirow{2}{*}{ Cr:Fe } \\
\cline { 2 - 4 } & $\mathbf{C r}$ & Fe & $\mathbf{O}$ & \\
\hline Initial & 16.3 & 70.4 & - & $1: 4.32$ \\
Untreated & 14.1 & 61.9 & 2.4 & $1: 4.37$ \\
Etched & 15.8 & 67.2 & - & $1: 4.25$ \\
Etched and anodized & 15.8 & 68.2 & 7.1 & $1: 4.31$ \\
\hline
\end{tabular}

It is of particular interest to discuss the electrochemical behavior of the preliminarily abraded electrode during anodizing in IL. Lower electrode potentials for this sample are evidently connected, with more effective removal of the natural oxide films by mechanical treatment. However, a key difference was observed in the surface texture of AA after galvanostatic anodization in IL. In this case, according to the SEM data, nano-cells were detected on the surface of the electrode (Figure 2a). A similar phenomenon was observed earlier on the surface of various electrodes during anodization in ionic liquids [17-19] and other non-aqueous electrolytes [29-31].

Therefore, the galvanostatic anodic oxidation leading to self-organization of the surface (in the form of hexagonal nano-cells) was detected. The use of hydrophobic IL is a crucial point. A hydrophobic IL containing a low content of water (below 5000 ppm) is an excellent medium for the formation of cellular nanostructures [16]. The pretreatment procedure is of utmost importance as well.

Therefore, the preliminarily abraded amorphous Fe70Cr15B15 alloy is the only sample that reveals the formation of hexagonal nanostructures on its surface appearing after anodization in IL.

\subsection{Electrochemical Corrosion in an $0.1 \mathrm{M} \mathrm{Na}_{2} \mathrm{SO}_{4}$ Aqueous Solution}

Iron and chromium are known to form solid solutions with unlimited solubility in the solid phase. This feature favors the production of binary alloys exhibiting high electrochemical corrosive stability in aqueous solutions. Indeed, crystalline Fe-Cr alloys show a significant electrochemical resistance to corrosion both with oxygen and hydrogen depolarizations.

The rate of electrochemical corrosion of single-phase systems drops dramatically with an increase in the atomic percentage of the alloying component $(\mathrm{Cr})$ according to the $n / 8$ Tammann's rule $(n=1,2$, $3, \ldots, 7)$ [32]. This implies that Fe-Cr binary systems with concentrations of the alloying component close to the first $(n=1)$ or the second threshold $(n=2)$ of stability should reveal a significant increase in corrosion potential.

The anticorrosive features of iron alloys are also known to be dependent on the surface solid solution crystallinity. The crystalline single-phase alloys exhibit better anticorrosive properties due to the homogeneity of the crystalline phase. The anticorrosive properties of 303,304 steels alloyed with $\mathrm{Cr}$ and amorphous Fe-Cr alloys show significant stability with respect to electrochemical corrosion as a result of the passive oxide film development [33,34].

Amorphous iron alloys containing more than 8 at. \% of chromium were reported to also show a high resistance to electrochemical pitting corrosion due to formation of a $\mathrm{CrO}_{\mathrm{x}} \mathrm{OH}_{\mathrm{y}} \cdot \mathrm{nH}_{2} \mathrm{O}$ protective film [34].

The composition and structural properties of the AA under study [35] are indicative of the high anticorrosive stability against aqueous solutions. Electrochemical oxidation of AA in aerated aqueous $0.1 \mathrm{M} \mathrm{Na}_{2} \mathrm{SO}_{4}$ solutions was studied for: 
1. Initial untreated AA sample;

2. Sample that was chemically etched with a benzoic acid $(0.013 \mathrm{M})$ /benzoate $(0.013 \mathrm{M})$ buffer in acetone (BB);

3. Sample chemically etched and electrochemically treated in IL;

4. Mechanically abraded sample;

5. Sample mechanically abraded and electrochemically treated in IL.

Figure 3a presents linear polarization curves obtained for the samples of the Fe70Cr15B15 metal glass electrode that were pretreated in a different manner in the $0.1 \mathrm{M} \mathrm{Na}_{2} \mathrm{SO}_{4}$ aerated aqueous solutions. There are distinctive features in the electrochemical behavior of the samples. An unambiguous cathodic shift in the voltage of the corrosion occurs for the preliminarily etched electrode. Therefore, the etching of the initial sample with BB (Figure 3a, curve 2) leads to a substantial deterioration in the anticorrosive properties of the material.

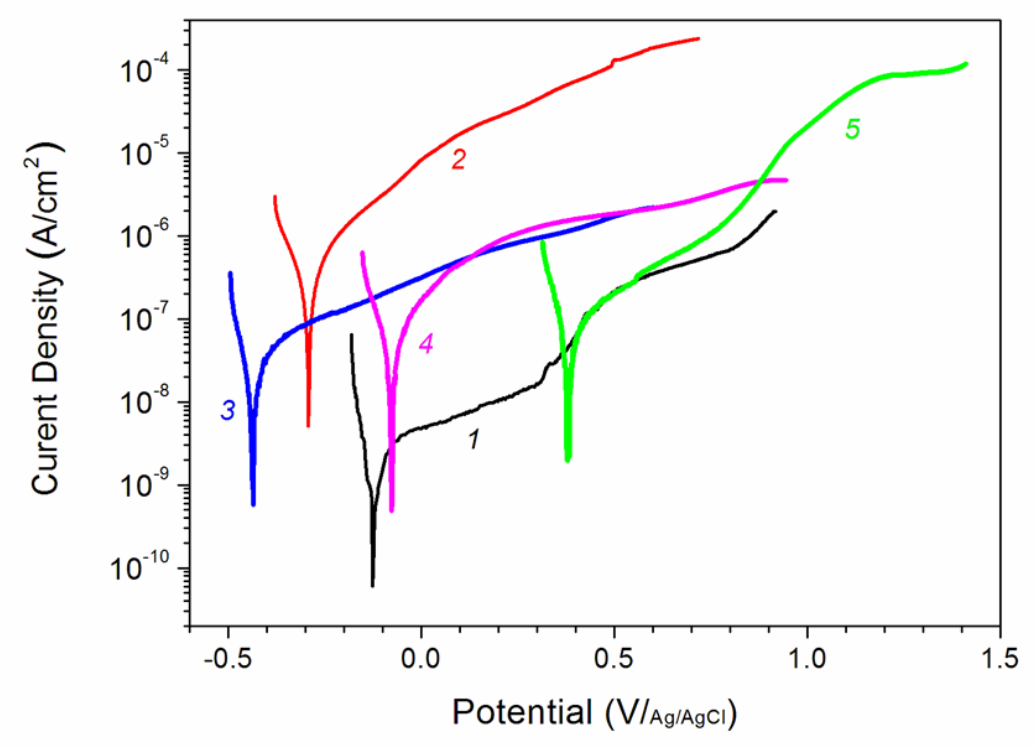

(a)

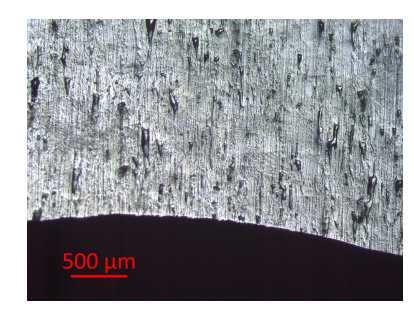

(b)

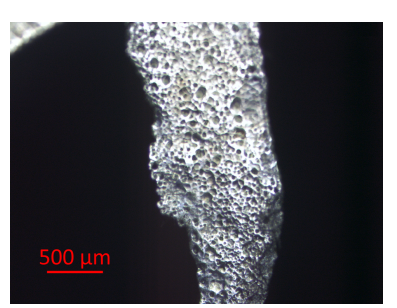

(c)

Figure 3. (a) Linear polarization curves (scanning rate $1 \mathrm{mV} \mathrm{s}^{-1}$ ) for the amorphous Fe70Cr15B15 alloy electrode in the $0.1 \mathrm{M} \mathrm{Na}_{2} \mathrm{SO}_{4}$ solution: 1-initial, 2-after the treatment of the alloy with a benzoic acid buffer in acetone $(0.013 \mathrm{M})$, 3-after the treatment with a benzoic acid buffer in acetone $(0.013 \mathrm{M})$ followed by anodic oxidation in IL at $i=12.5 \mathrm{~mA} \mathrm{~cm}^{-2}$ for $100 \mathrm{~s}$, 4-after mechanical abrasion, and 5-after mechanical abrasion followed by anodic oxidation in IL at $i=12.5 \mathrm{~mA} \mathrm{~cm}{ }^{-2}$ for $100 \mathrm{~s}$; Optical photo images of: (b) initial amorphous Fe70Cr15B15 alloy and (c) Fe70Cr15B15 amorphous alloy pretreated with $\mathrm{BB}$ in acetone followed by the electrochemical oxidation in the $0.1 \mathrm{M} \mathrm{Na}_{2} \mathrm{SO}_{4}$ aqueous aerated solution.

The following anodization of this sample in IL results even in a much more pronounced decrease in the corrosion potential $(-439 \mathrm{mV}$ ) (Figure 3a, curve 3). It is reasonable to note that the surface oxide film removal due to the treatment with the BB solution leads also to a decrease in the polarization resistance (Table 2). 
Table 2. Corrosion potentials $\left(E_{c o r r}\right)$ and polarization resistances $(P R)$ for the electrochemical oxidation of the samples of the Fe70Cr15B15 amorphous alloy in the $0.1 \mathrm{M} \mathrm{Na}_{2} \mathrm{SO}_{4}$ aqueous solution (295 K).

\begin{tabular}{ccc}
\hline Sample & $\boldsymbol{E}_{\text {corr }} \mathbf{( m V )}$ & $\mathbf{P R} \times \mathbf{1 0}^{\mathbf{5}} \mathbf{( \mathbf { O h m } )}$ \\
\hline AA & -125 & 30.3 \\
BB & -293 & 7.67 \\
Sample chemically etched and electrochemically treated in IL & -439 & 8.63 \\
Mechanically abraded sample & -79.4 & 3.88 \\
Sample mechanically abraded and electrochemically treated in IL & +379 & 2.64 \\
\hline
\end{tabular}

Changes in the surface state of the sample after chemical etching with BB followed by electrochemical oxidation in the $0.1 \mathrm{M} \mathrm{Na}_{2} \mathrm{SO}_{4}$ aqueous solution are depicted in Figure $3 b$,c. As seen in Figure 3c, anodic oxidation of the amorphous Fe70Cr15B15 alloy (preliminarily treated with BB) in an aqueous solution results only in deep pitting of the surface, as was observed for glassy Fe-40Ni-14P-6B alloy [36].

In contrast, the corrosion potentials after mechanical abrasion $(-79 \mathrm{mV})$ and particularly after the subsequent electrochemical oxidation of the abraded electrode $(+379 \mathrm{mV})$ in IL are significantly shifted to the anodic region. The $P R$ value also decreases compared to that for the initial sample.

The substantial improvement in the anticorrosive properties of the abraded and anodized metal glass is accompanied by certain surface structure changes. This is clearly demonstrated in Figure $2 b$, in which hexagonal nanostructures are observed on the surface of the abraded Fe70Cr15B15 metal glass electrode after being anodized in IL.

It should be noted that self-organized hexagonal nano-cells are formed on the surface of the abraded Fe70Cr15B15 metal glass only after anodization in IL (Figure 2a). The following electrochemical oxidation of this sample in the $0.1 \mathrm{M} \mathrm{Na}_{2} \mathrm{SO}_{4}$ aqueous solution brings about an oxide film growth on the background of the hexagonal nano-cells (Figure 2b).

The deterioration of the anticorrosive properties of AA after etching by $\mathrm{BB}$ originates from the partial removal of the incoherent oxide film. The subsequent anodization of the etched alloy electrode results in the detachment of the protective oxide film from the alloy and in the increase in the corrosion current due to the developing oxide-free metal surface. This phenomenon was also observed earlier for other samples [26,37].

In accordance with the results of polarization measurements, only the alloy covered with a natural passive oxide film demonstrates a relatively high corrosion potential and low current of corrosion (Table 2). Perhaps the protective effect of the surface oxide film is due to the homogeneity of the alloy surface texture and higher rate of the oxide growth connected with the highly active amorphous structure.

The natural oxide film formed on the AA surface is heterogeneous and consists of layers [33,37]. The presence of different oxide films is seen from the shape of the linear curves for the untreated amorphous Fe70Cr15B15 alloy (curve 1, Figure 3a). As compared with the similar curves obtained for the etched and anodized electrodes, there are some waves (at +0.32 and $+0.82 \mathrm{~V}$ ) on curve 1 for untreated AA attributed to the consecutive removal of the surface oxide layers $[33,34]$.

The order of the removal of the oxide films from the AA surface and the sequence of the sudden potential changes obviously depend on the properties and types of oxide films. The differences in the corrosion potentials for the chemically etched (curve 2, Figure 3a) and etched and anodized (curve 3) electrodes point to the difference in the alloy surface composition. The larger cathodic shift in the corrosion potential in the case of the chemically etched and anodized AA (Table 2) is likely due to the presence of a highly coherent oxide layer being left over the surface after chemical etching (curve 2). Otherwise, the corrosion potentials obtained for the etched $(-293 \mathrm{mV})$ and for the etched and anodized $(-439 \mathrm{mV})$ electrodes would be the same.

Thus, the chemical etching only results in a partial removal of the less cohered external oxide layer. The subsequent anodizing of the alloy that is preliminarily chemically etched in IL leads to the 
oxide-free surface and the following corrosion potential growth is connected with the electrochemical oxidation of the alloy.

In addition to the compact passive film, the nanostructure also plays a critical role in the excellent corrosion resistance of the eutectic high entropy alloy (EHEA). Pit nucleation is essentially an event of electrochemical instability and originates from the coupling of local anodic sites in the presence of perturbations in an electric field and the concentration of attacking ions [38].

Therefore, the untreated three-component amorphous alloy is stable enough relative to the corrosion compared with the amorphous $\mathrm{Fe}_{\mathrm{x}} \mathrm{Cr}_{1-\mathrm{x}}$ alloy studied earlier [34].

\section{Conclusions}

The influence of the preliminary treatment of the amorphous Fe70Cr15B15 alloy on the surface morphology and electrochemical behavior in aqueous solutions of $\mathrm{Na}_{2} \mathrm{SO}_{4}$ and in IL 1-butyl-3-methylimidazolium tetrafluoroborate was established by means of linear polarization investigations and galvanostatic anodic oxidation studies.

The treatment of the amorphous Fe70Cr15B15 alloy with citric acid, benzoic acid buffer, and $\mathrm{NaOH}$ acetone solutions results in total removal of the natural oxide films. The total removal of the natural oxides before anodization in aqueous solutions and IL results only in etching (no cellular nanostructure) of the alloy surface. The decay of the continuity of the superficial oxide films (mechanical abrasion) favors the appearance of hexagonal nanostructures (cells) on the electrode surface after the subsequent anodization in IL. The sample with hexagonal nanostructures obtained after anodization of the mechanically abraded sample demonstrates a more significant anodic shift in the corrosion potential $\left(E_{\text {corr }}=+379 \mathrm{mV}\right)$ compared with that for the initial alloy $\left(E_{\text {corr }}=-125 \mathrm{mV}\right)$. The formation of hexagonal nanostructures provides a better possibility to produce uniform oxide layers (due to the nanostructure) compared to the other samples. The significant anodic shift in the corrosion potential is observed for this reason. The detachment of the anodic oxide film from untreated Fe-amorphous alloy under anodization in ionic liquid was revealed for the first time.

Author Contributions: Investigation, V.S., I.K., N.R. and D.K.; analysis, K.K. and S.P.; writing-Original draft, O.L., D.K. and A.Z.; writing-Review and editing, L.K. and S.D. All authors have read and agreed to the published version of the manuscript.

Funding: This work was supported by the Ministry of Education and Science of the Russian Federation in the framework of Increase Competitiveness Program of NUST «MISiS» (grant no. K2-2019-005).

Conflicts of Interest: The authors declare no conflict of interest.

\section{References}

1. Ghidelli, M.; Gravier, S.; Blandin, J.-J.; Djemia, P.; Mompiou, F.; Abadias, G.; Raskin, J.-P.; Pardoen, T. Extrinsic mechanical size effects in thin ZrNi metallic glass films. Acta Mater. 2015, 90, 232-241. [CrossRef]

2. Zhao, Y.H.; Luo, C.Y.; Xi, X.K.; Zhao, D.Q.; Pan, M.X.; Wang, W.H. Synthesis and elastic properties of amorphous steels with high Fe content. Intermetallics 2006, 14, 1107-1111. [CrossRef]

3. Louzguine-Luzgin, D.V.; Ketov, S.V.; Trifonov, A.S.; Churymov, A.Y. Surface structure and properties of metallic glasses. J. Alloys Compd. 2018, 742, 512-517. [CrossRef]

4. Imai, K.; Zhou, X.; Liu, X. Application of Zr and Ti-based bulk metallic glasses for orthopaedic and dental device materials. Metals 2020, 10, 203. [CrossRef]

5. Winters, G. Stainless Steels for Medical and Surgical Applications; Nutt, M., Ed.; ASTM International: West Conshohocken, PA, USA, 2003. [CrossRef]

6. Wang, S.L.; Yi, S. The corrosion behaviors of Fe-based bulk metallic glasses in a sulfuric solution at $70{ }^{\circ} \mathrm{C}$. Intermetallics 2010, 18, 1950-1953. [CrossRef]

7. Huynh, V.; Ngo, N.K.; Golden, T.D. Surface activation and pretreatments for biocompatible metals and alloys used in biomedical applications. Int. J. Biomater. 2019, 2019, 3806504. [CrossRef] 
8. Hernandez-Rodriguez, M.A.L.; Laverde-Cataño, D.A.; Lozano, D.; Martinez-Cazares, G.; Bedolla-Gil, Y. Influence of boron addition on the microstructure and the corrosion resistance of CoCrMo Alloy. Metals 2019, 9, 307. [CrossRef]

9. Yang, M.; Zhang, D. Effect of surface treatment on the interfacial contact resistance and corrosion resistance of FeNiCr alloy as a bipolar plate for polymer electrolyte membrane fuel cells. Energy 2014, 64, 242-247. [CrossRef]

10. O'Laoire, C.; Timmins, B.; Kremer, L.; Holmes, J.D.; Morris, M.A. Analysis of the acid passivation of stainless steel. Anal. Lett. 2006, 39, 2255-2271. [CrossRef]

11. Sowmiah, S.; Srinivasadesikan, V.; Tseng, M.-C.; Chu, Y.-H. On the chemical stabilities of ionic liquids. Molecules 2009, 14, 3780-3813. [CrossRef]

12. Plechkova, N.V.; Seddon, K.R. Applications of ionic liquids in the chemical industry. Chem. Soc. Rev. 2008, 37, 123-150. [CrossRef]

13. Abbott, A.P.; Capper, G.; McKenzie, K.J.; Ryder, K.S. Voltammetric and impedance studies of the electropolishing of type 316 stainless steel in a choline chloride based ionic liquid. Electrochim. Acta 2006, 51, 4420-4425. [CrossRef]

14. Lebedeva, O.; Dzhungurova, G.; Kultin, D.; Kustov, L.; Zakharov, A.; Kalmykov, K.; Chernikova, E.; Krasovskii, V. Ionic liquids based on imidazolium cation in platinum and titanium electropolishing. Green Chem. 2011, 13, 1004-1008. [CrossRef]

15. Uda, T.; Tsuchimoto, K.; Nakagawa, H.; Murase, K.; Nose, Y.; Awakura, Y. Electrochemical polishing of metallic titanium in ionic liquid. Mater. Trans. 2011, 52, 2061-2066. [CrossRef]

16. Loftis, J.D.; Abdel-Fattah, T.M. Nanoscale electropolishing of high-purity nickel with an ionic liquid. Int. J. Miner. Metall. Mater. 2019, 26, 649-656. [CrossRef]

17. Kalmykov, K.B.; Dmitrieva, N.E.; Lebedeva, O.K.; Root, N.V.; Kultin, D.Y.; Kustov, L.M. Formation of a regular cellular structure on the surface of $\mathrm{Zr}_{67} \mathrm{Ni}_{30} \mathrm{Si}_{3}$ alloy at electrochemical polishing in ionic liquids. Russ. Chem. B 2016, 65, 2801-2804. [CrossRef]

18. Lebedeva, O.; Kultin, D.; Kudryavtsev, I.; Root, N.; Kustov, L. The role of the initial hexagonal self-ordering in anodic nanotube growth in ionic liquid. Electrochem. Commun. 2017, 75, 78-81. [CrossRef]

19. Lebedeva, O.; Kudryavtsev, I.; Kultin, D.; Dzhungurova, G.; Kalmykov, K.; Kustov, L. Self-organized hexagonal nanostructures on nickel and steel formed by anodization in 1-Butyl-3-methylimidazolium bis(triflate)imide. J. Phys. Chem. C 2014, 118, 21293-21298. [CrossRef]

20. Idrissi, H.; Gravier, S.; Ghidelli, M.; Blandin, J.-J.; Raskin, J.-P.; Schryvers, D.; Pardoen, T. Homogeneous flow and size dependent mechanical behavior in highly ductile Zr65Ni35 metallic glass films. Acta Mater. 2017, 131, 246-259. [CrossRef]

21. Makletsov, V.G.; Kanunnikova, O.M.; Lubnin, A.N. The effect of oxidation of amorphous $\mathrm{Fe}_{70} \mathrm{Cr}_{15} \mathrm{~B}_{15}$ alloy on its corrosion behavior in the acidic sulfate media. Prot. Met. 2006, 42, 555-559. [CrossRef]

22. Zhijie, Y.; Jinfu, L.; Shunrong, H.; Honghua, W.; Yaohe, Z. Study of the crystallization kinetics of $Z{ }_{60} \mathrm{Al}_{15} \mathrm{Ni}_{25}$ bulk glassy alloy by differential scanning calorimetry. Mater. Trans. 2003, 44, 709-712. [CrossRef]

23. Wood, G.; Stringer, J. The adhesion of growing oxide scales to the substrate. J. Phys. IV 1993, 3, C9-65-C9-74. [CrossRef]

24. Liu, Y.; Skeldon, P.; Thompson, G.E.; Zhou, X.; Habazaki, H.; Shimizu, K. Influence of surface treatment on detachment of anodic films from Al-Mg alloys. Corros. Sci. 2001, 43, 2349-2357. [CrossRef]

25. Liu, L.Y.; Alexander, M.; Koroleva, E.; Skeldon, P.; Thompson, G.E.; Bailey, P.; Noakes, T.C.Q.; Shimizu, K.; Habazaki, H. Detachment of alumina films from aluminium by100 keV H+ions. Surf. Interface Anal. 2002, 33, 318-321. [CrossRef]

26. Gentile, M.; Koroleva, E.V.; Skeldon, P.; Thompson, G.E.; Bailey, P.; Noakes, T.C.Q. Influence of grain orientation on Zinc enrichment and surface morphology of Al-Zn alloy. Surf. Interface Anal. 2010, 42, $287-292$. [CrossRef]

27. Pisarek, M.; Kedzierzawski, P.; Janik-Czachor, M.; Kurzydlowski, K.J. Effect of hydrostatic extrusion on passivity breakdown on 303 austenitic stainless steel in chloride solution. J. Solid State Electrochem. 2009, 13, 283-291. [CrossRef]

28. Naka, M.; Hashimoto, K.; Masumoto, T. Effect of metalloidal elements on corrosion resistance of amorphous iron-chromium alloys. J. Non Cryst. Solids 1978, 28, 403-413. [CrossRef] 
29. Bandyopadhyay, S.; Miller, A.E.; Chang, H.C.; Banerjee, G.; Yuzhakov, V.; Yue, D.-F.; Ricker, R.E.; Jones, S.; Eastman, J.A.; Baugher, E.; et al. Electrochemically assembled quasi-periodic quantum dot arrays. Nanotechnology 1996, 7, 360-371. [CrossRef]

30. Hernandez-Lopez, J.M.; Nemcova, A.; Zhong, X.I.; Liu, H. Formation of barrier-type anodic films on ZE41 magnesium alloy in a fluoride/glycerol electrolyte. Electrochim. Acta 2014, 138, 124-131. [CrossRef]

31. Vignal, V.; Roux, J.C.; Flandrois, S.; Fevrier, A. Nanoscopic studies of stainless steel electropolishing. Corros. Sci. 2000, 42, 1041-1053. [CrossRef]

32. Shcherbakov, I. Theory of dissolution of binary alloys and the tamman rule. Prot. Met. 2005, 41, 30-35. [CrossRef]

33. Zheng, Z.J.; Gao, Y.; Gui, Y.; Zhu, M. Corrosion behavior of nanocrystalline 304 stainless steel prepared by equal channel angular pressing. Corros. Sci. 2012, 54, 60-67. [CrossRef]

34. Nowak, W.B.; Okorie, B.A. Electrochemical (Corrosion) behavior of amorphous/microcrystalline iron plated Fe-Cr alloy films. Corrosion 1982, 38, 314-318. [CrossRef]

35. Pokatilov, V.S.; Dmitrieva, T.G.; Pokatilov, V.V.; Kitaev, V.V. Local structure of Fe70Cr15B15 X-ray amorphous alloy. Bull. Russ. Acad. Sci. Phys. 2012, 76, 840-842. [CrossRef]

36. Archer, M.D.; McKim, R.J. Unusual stress-corrosion cracks observed in glassy Fe-40Ni-14P-6B alloy. J. Mater. Sci. 1983, 18, 1125-1135. [CrossRef]

37. Zhou, X.; Habazaki, H.; Shimizu, K.; Skeldon, P.; Thompson, G.E.; Wood, G.C. Enrichment-dependent anodic oxidation of zinc in Al-Zn alloys. Corros. Sci. 1996, 38, 1563-1577. [CrossRef]

38. Shuang, S.; Ding, Z.Y.; Chung, D.; Shib, S.Q.; Yang, Y. Corrosion resistant nanostructured eutectic high entropy alloy. Corros. Sci. 2019, 164, 108315. [CrossRef]

(C) 2020 by the authors. Licensee MDPI, Basel, Switzerland. This article is an open access article distributed under the terms and conditions of the Creative Commons Attribution (CC BY) license (http://creativecommons.org/licenses/by/4.0/). 